\title{
Worsened hypertension control induced by aripiprazole
}

This article was published in the following Dove Press journal:

Neuropsychiatric Disease and Treatment

12 April 2013

Number of times this article has been viewed

\author{
Norio Yasui-Furukori \\ Akira Fujii \\ Department of Neuropsychiatry, \\ Graduate School of Medicine, \\ Hirosaki University, Hirosaki, Japan
}

\begin{abstract}
Aripiprazole is widely used in the treatment of schizophrenia and bipolar disorders. Although antipsychotics generally have hypotensive effects, two cases were identified that demonstrated hypertension during the switch from other antipsychotics to aripiprazole. The hypertensive state of these patients recovered after switching back to other antipsychotics, and these cases suggest that aripiprazole may lead to hypertension.
\end{abstract}

Keywords: hypertension, aripiprazole, dopamine antagonist, 5-HT1a

\section{Introduction}

Hypotension is a known effect of atypical antipsychotics. In addition, the prevalence of orthostatic hypotension in the elderly is estimated to be between 5\% and 33\% and increases with age. ${ }^{1}$ Orthostatic hypotension is a common side effect of a number of medications, including antipsychotic drugs, and a major contributing factor to the occurrence of falls with adverse consequences, such as bone fractures, injuries, functional decline, dependency, and death. Furthermore, the extent to which antipsychotic drugs cause hypotension differs, and low-potency conventional antipsychotics and clozapine are among the more problematic. However, there is little information on acute hypertension resulting from antipsychotic drugs.

Aripiprazole is a potent (high-affinity) partial dopamine D2 agonist, a serotonin 5-HT1A agonist and a 5-HT2A antagonist. ${ }^{2}$ It acts as a functional antagonist of D2 receptors under hyperdopaminergic conditions but exhibits functional agonistic properties under hypodopaminergic conditions. ${ }^{3}$ Here, two cases of acute hypertension during the switch from other antipsychotics to aripiprazole are reported.

\section{Case one}

This patient was a 69-year-old woman with a 35-year history of schizophrenia. Her primary symptoms included auditory hallucinations, persecution mania, and self-talking. Her mental condition had been maintained with $2 \mathrm{mg}$ /day of risperidone or 8-16 $\mathrm{mg}$ /day of perospirone for several years. Hypertension (systolic blood pressure $>180 \mathrm{mmHg}$ ) had developed 2 years previously and had been treated with a salt reduction policy and amlodipine at $5 \mathrm{mg} /$ day. As a result, her blood pressure was controlled, and amlodipine was discontinued after 1 year. Due to akathisia, perospirone at $8 \mathrm{mg}$ /day was changed to quetiapine at $100 \mathrm{mg} /$ day or olanzapine at $5 \mathrm{mg} /$ day; however, these drugs were withdrawn because of sedation. Thus, aripiprazole was initiated, but she suffered from dizziness, headache, and anacatesthesia as well
Correspondence: Norio Yasui-Furukor Department of Neuropsychiatry, Graduate School of Medicine, Hirosaki University, Hirosaki 036-8562, Japan

Tel +8I I72 395066

Fax +81172395067

Email yasufuru@cc.hirosaki-u.ac.jp 
as hypertension (200/110 $\mathrm{mmHg}$ ). Thus, aripiprazole was changed to risperidone at $2 \mathrm{mg} /$ day, and her blood pressure immediately dropped to $130 / 80 \mathrm{mmHg}$. The clinical course is summarized in Figure 1.

\section{Case two}

This patient was a 63-year-old man with a 9-year history of bipolar disorders. His primary symptoms included depressed mood, insomnia, appetite loss, concentration difficulty, and suicidal ideation. Manic episodes were also observed 2 years previously. He was diagnosed with hypertension (systolic blood pressure $>180 \mathrm{mmHg}$ ) 1 year previously and treated with a salt reduction policy and nifedipine at $10 \mathrm{mg} /$ day. Consequently, his blood pressure was controlled, and nifedipine was discontinued after 3 months of treatment. His mental status was depressed with lithium treatment at $600 \mathrm{mg} /$ day, paroxetine at $30 \mathrm{mg} /$ day and olanzapine at $5 \mathrm{mg} /$ day. Because of persistent depressive episodes, olanzapine at $5 \mathrm{mg} /$ day was switched to aripiprazole at $3 \mathrm{mg} /$ day. When the dose of aripiprazole escalated to $24 \mathrm{mg} /$ day, his blood pressure increased to $180 / 90 \mathrm{mmHg}$ with headache, and he was inarticulate. Although his hypertension was treated with amlodipine at $5 \mathrm{mg} /$ day and propranolol at $60 \mathrm{mg} /$ day, his blood pressure did not change. However, after aripiprazole withdrawal, his blood pressure dropped to $147 / 100 \mathrm{mmHg}$. The clinical course is summarized in Figure 2.

\section{Discussion}

In the two cases presented here, hypertension after aripiprazole initiation but recovery after aripiprazole discontinuation was observed. Based on these clinical courses, it was concluded that the hypertension worsened due to aripipra-

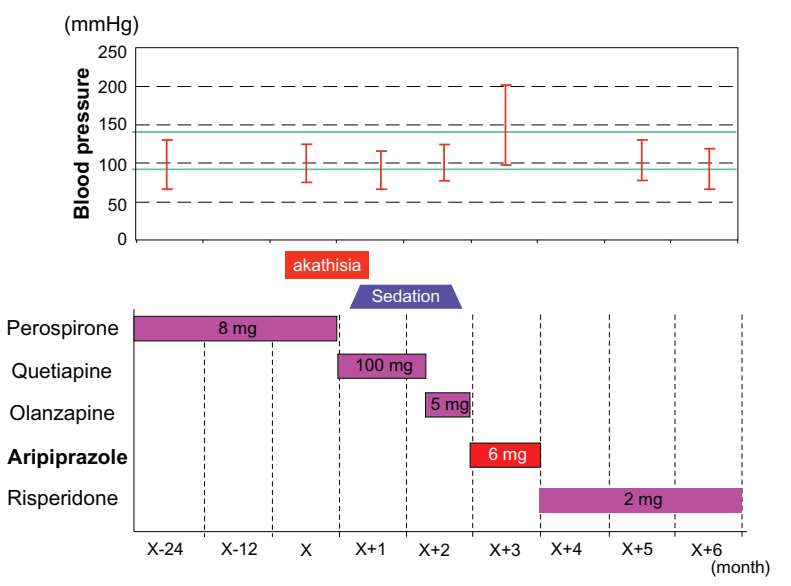

Figure I Clinical course of case one.

Notes: Upper green line indicates limit for systolic blood pressure; lower green line indicates limit for diastolic blood pressure.

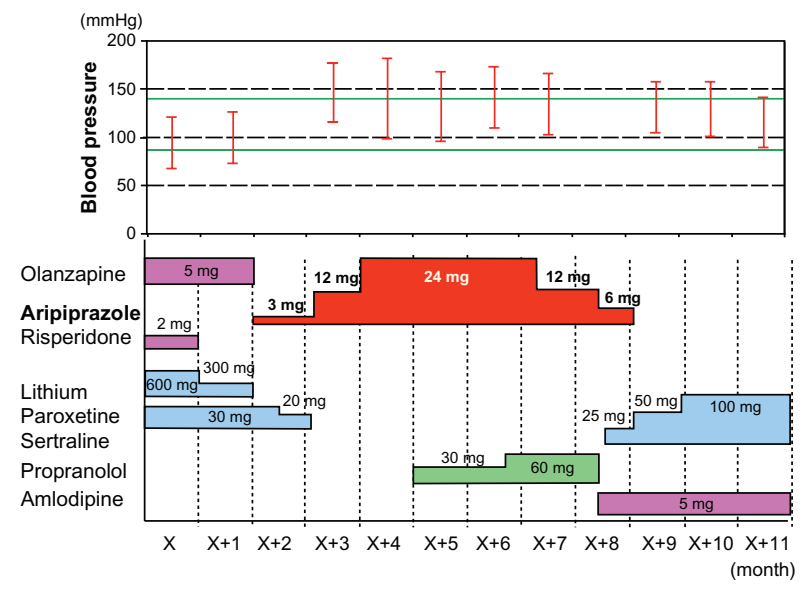

Figure 2 Clinical course of case two.

Notes: Upper green line indicates limit for systolic blood pressure; lower green line indicates limit for diastolic blood pressure.

zole, although withdrawal effects of previous antipsychotics cannot be ruled out.

Antipsychotics are known to cause the metabolic syndrome of insulin resistance, hyperlipidemia, and hypertension. Thus, addressing blood pressure as well as glycemia and lipid levels is an important step in the management of patients taking aripiprazole. In addition, according to the product information, the most frequently reported adverse reaction in clinical trials was headache (Otsuka Pharmaceutical Co, Ltd, Tokyo, Japan). Headache could have been a symptom of hypertension. In fact, the patients experienced headaches while having hypertension.

The dopamine receptor in vascular smooth muscle participates in vasodilatation, but the possibility that aripiprazole causes vascular smooth muscle to shrink as an antagonist under conditions in which dopamine is superabundant and high blood pressure is induced has been hypothesized. However, there is no D2 receptor in vascular smooth muscle, although there are D1 receptors. Because aripiprazole has extremely low affinity for the D1 receptor, it is unlikely that the high blood pressure observed with aripiprazole was mediated through the D1 receptor.

Although Hirose et al reported that aripiprazole acts as an antagonist for the 5-HT2A receptor, ${ }^{4}$ Davies et al indicated that aripiprazole is a partial agonist for 5 -HT2A. ${ }^{5}$ Because the 5-HT2A receptor participates in the contraction of vascular smooth muscle, the possibility that vascular smooth muscle shrank as a result of aripiprazole acting as an agonist for 5-HT2A and inducing a rise in blood pressure has been hypothesized. The involvement of $\alpha-1 \mathrm{~A}$ adrenergic receptors cannot be ruled out because aripiprazole has high affinity for $\alpha-1 \mathrm{~A}$ adrenergic receptors, ${ }^{6}$ which is related to 
malignant hypertension. ${ }^{7}$ In addition, nitric oxide is known to suppress blood pressure. An in vitro study using brain macrophages has suggested that aripiprazole inhibits nitric oxide production from microglial cells. ${ }^{8}$ Therefore, suppression of nitric oxide by aripiprazole may result in the patient's hypertension.

However, only four reports have demonstrated high blood pressure induced by aripiprazole. Borras et al reported hypertension $(220 / 110 \mathrm{mmHg})$ and tachycardia during aripiprazole treatment at $30 \mathrm{mg} /$ day in a schizophrenic patient, which disappeared after aripiprazole discontinuation and propranolol administration. ${ }^{9}$ Pitchot and Ansseau indicated that the addition of $5 \mathrm{mg}$ of aripiprazole to $150 \mathrm{mg}$ of venlafaxine in a patient with major depressive disorder led to hypertension $(200 / 110 \mathrm{mmHg})$ and that aripiprazole discontinuation led to normalized blood pressure within 48 hours. ${ }^{10}$ Hsiao et al showed high blood pressure $(220 / 110 \mathrm{mmHg})$, headache, and dizziness after treatment with $90 \mathrm{mg}$ of duloxetine and $5 \mathrm{mg}$ /day of aripiprazole in a depressed patient. ${ }^{11}$ Moreover, the administration of nifedipine and ramipril did not have an antihypertensive effect, and blood pressures were normalized with a reduction in aripiprazole from $5 \mathrm{mg} /$ day to $2.5 \mathrm{mg}$ /day. In addition, Bat-Pitault and Delorme reported hypertension $(190 / 110 \mathrm{mmHg})$ in an adolescent patient, which was most likely induced by aripiprazole. ${ }^{12}$ Although Pitchot and Ansseau and Hsiao et al discussed the influence of a concomitant drug, ${ }^{10,11}$ case one in the current report received aripiprazole only, and high blood pressure developed after aripiprazole. Therefore, it is not likely that the influence of the concomitant drug induced hypertension. Pitchot and Ansseau suggested the association with a prior history of cardiovascular disease, including coronary disease, ${ }^{10}$ and the two cases in the current report also revealed a history of hypertension. Therefore, blood pressure variation must be carefully monitored when administering aripiprazole to patients with a previous history of cardiovascular disease.

\section{Conclusion}

This report presented two cases demonstrating high blood pressure after aripiprazole initiation, although blood pressures were normalized following aripiprazole interruption. Although the mechanism underlying the rise in blood pressure remains unclear, careful monitoring of blood pressure variations when administering aripiprazole to patients previously treated for high blood pressure is necessary.

\section{Disclosure}

The authors report no conflicts of interest in this work.

\section{References}

1. Verhaeverbeke I, Mets T. Drug-induced orthostatic hypotension in the elderly: avoiding its onset. Drug Saf. 1997;17(2):105-118.

2. Jordan S, Koprivica V, Chen R, Tottori K, Kikuchi T, Altar CA. The antipsychotic aripiprazole is a potent, partial agonist at the human 5-HT1A receptor. Eur J Pharmacol. 2002;441(3):137-140.

3. Fujikawa M, Nagashima M, Inoue T, Yamada K, Furukawa T. Partial agonistic effects of OPC-14597, a potential antipsychotic agent, on yawning behavior in rats. Pharmacol Biochem Behav. 1996;53(4):903-909.

4. Hirose T, Uwahodo Y, Yamada S, et al. Mechanism of action of aripiprazole predicts clinical efficacy and a favourable side-effect profile. J Psychopharmacol. 2004;18(3):375-383.

5. Davies MA, Sheffler DJ, Roth BL. Aripiprazole: a novel atypical antipsychotic drug with a uniquely robust pharmacology. CNS Drug Rev. 2004; 10(4):317-336.

6. Shapiro DA, Renock S, Arrington E, et al. Aripiprazole, a novel atypical antipsychotic drug with a unique and robust pharmacology. Neuropsychopharmacology. 2003;28(8):1400-1411.

7. Fu ML, Herlitz H, Wallukat G, et al. Functional autoimmune epitope on $\alpha 1$-adrenergic receptors in patients with malignant hypertension. Lancet. 1994;344(8938):1660-1663.

8. Kato T, Mizoguchi Y, Monji A, et al. Inhibitory effects of aripiprazole on interferon- $\gamma$-induced microglial activation via intracellular $\mathrm{Ca} 2+$ regulation in vitro. $J$ Neurochem. 2008;106(2):815-825.

9. Borras L, Constant EL, Eytan A, Huguelet P. Hypertension and aripiprazole. Am J Psychiatry. 2005;162(12):2392.

10. Pitchot W, Ansseau M. Aripiprazole, hypertension, and confusion. J Neuropsychiatry Clin Neurosci. 2010;22(1):123. E33.

11. Hsiao YL, Chen SJ, Shen TW, Chang CH, Chen ST. Aripiprazole augmentation induced hypertension in major depressive disorder: a case report Prog Neuropsychopharmacol Biol Psychiatry. 2011;35(1):305-306.

12. Bat-Pitault F, Delorme R. Aripiprazole and hypertension in adolescents J Child Adolesc Psychopharmacol. 2009;19(5):601-602.
Neuropsychiatric Disease and Treatment

\section{Publish your work in this journal}

Neuropsychiatric Disease and Treatment is an international, peerreviewed journal of clinical therapeutics and pharmacology focusing on concise rapid reporting of clinical or pre-clinical studies on a range of neuropsychiatric and neurological disorders. This journal is indexed on PubMed Central, the 'PsycINFO' database and CAS

\section{Dovepress}

The manuscript management system is completely online and includes a very quick and fair peer-review system, which is all easy to use. Visit http://www.dovepress.com/testimonials.php to read real quotes from published authors. 